\title{
Intraluminal instillation of urokinase and autologous plasma: a method to unblock occluded central venous ports Georg Seifert*1, Hanno Riess ${ }^{2}$, Karl Seeger ${ }^{1}$, Guenter Henze ${ }^{1}$ and Anja Borgmann ${ }^{1}$
}

\author{
Address: ${ }^{1}$ Department of Paediatric Oncology/Haematology, Charité - Universitätsmedizin Berlin, Germany and ${ }^{2}$ Department of Haematology \\ and Oncology, Charité - Universitätsmedizin Berlin, Germany \\ Email: Georg Seifert* - georg.seifert@charite.de; Hanno Riess - hanno.riess@charite.de; Karl Seeger - karl.seeger@charite.de; \\ Guenter Henze - guenter.henze@charite.de; Anja Borgmann - anja.borgmann@charite.de \\ * Corresponding author
}

Published: 24 April 2006

BMC Cancer 2006, 6:103 doi:10.1 186/147|-2407-6-103

This article is available from: http://www.biomedcentral.com//47/-2407/6/103

(C) 2006 Seifert et al; licensee BioMed Central Ltd.

This is an Open Access article distributed under the terms of the Creative Commons Attribution License (http://creativecommons.org/licenses/by/2.0), which permits unrestricted use, distribution, and reproduction in any medium, provided the original work is properly cited.

\begin{abstract}
Background: Therapeutic use and effective function of recombinant urokinase ( $r$-UK) for occluded ports need the presence of plasminogen.

Methods: As a therapeutic proof of principle, we demonstrate that the use of r-UK and autologous plasma effectively reestablishes the function of occluded central venous ports (CVP) resistant to routine management of catheter occlusion. Five patients with occluded ports resistant to the routine management were treated.
\end{abstract}

Results: All patients were successfully treated with thrombolytic therapy using intraluminal instillation of $r$-UK and autologous plasma.

Conclusion: Instillation of $r$-UK and autologous plasma is a safe and effective method for management of CVP occlusion.

\section{Background}

Regular application of plasma products or chemotherapy is often complicated by catheter-related problems such as blockage. Especially in children, an effective and simple reestablishment of catheter patency is important. Maintenance of catheter function is usually achieved with flushing (sodium chloride and/or heparin) or urokinase instillation $[1,2]$. In the majority of cases low-dose urokinase therapy is a safe and efficacious treatment for catheter occlusion, frequently obviating the need for catheter removal. However, in some cases of occluded central venous ports (CVP), r-UK instillation is not effective. Because effective therapeutic function of $\mathrm{r}$-UK requires the presence of plasminogen (see Figure 1) contained in human plasma, we combined autologous plasma and rUK for treatment of occluded CVP in adult and paediatric patients.

\section{Methods}

Five patients with occluded CVP were treated. Patient characteristics are given in Table 1. After up to eight attempts every 15 minutes with drawing and pressing to remove the CVP occlusion with sodium chloride and/or heparin and subsequently with $10 \mathrm{mg}$ recombinant tissue plasminogen activator (r-tPA) and 5.000 IU r-UK, we used a combination of $2 \mathrm{ml}$ of the patient's plasma and 10.000 IU r-UK (Medac GmbH, Germany) dissolved in $1 \mathrm{ml}$ sodium chloride. The plasma was obtained by centrifuga- 


\section{Plasminogen}

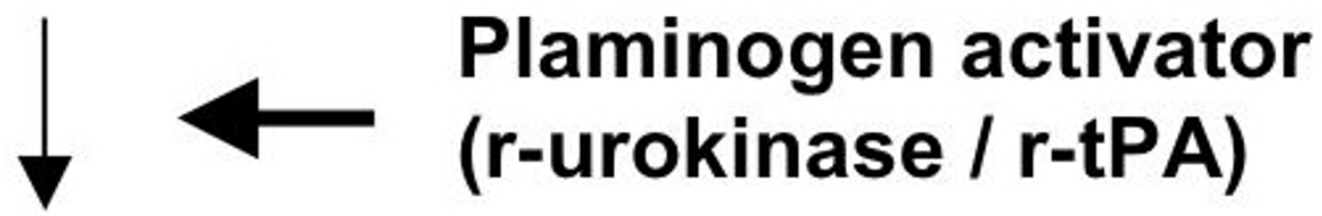

\section{Plasmin}<smiles>[3H]C</smiles>

\section{Fibrin}

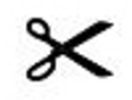

Fibrin Degradation Products

Figure I

Fibrinolytic System.

tion at $1100 \mathrm{~g}$ for 10 minutes in a sterile syringe. Next, the combination of autologous plasma and r-UK were slowly mixed for 2 minutes within a $5 \mathrm{ml}$ - syringe before application. The combination was slowly instilled, whereby a volume slightly above the CVP volume was injected. Thirty minutes after instillation, success was assessed by attempting to aspirate the combination and residual clot with an empty, sterile syringe. Up to three further attempts of aspiration were made. If the aspiration was successful, the catheter lumen was immediately flushed with $10 \mathrm{ml}$ sodium chloride and/or heparin. Informed consent was obtained from patients, and, if necessary, from parents, as approved by the Institutional Ethical Committee.

\section{Results}

We report on five patients with an CVP occlusion that could not be managed by routine procedures. All patients had internal jugular CVPs, which had all been implanted in a surgical unit. The indications for CVP placement were regular infusion of plasma products, chemotherapy and antibiotics. We tested the new method described in this paper as a last resort before catheter replacement. All instillations resulted in successful reestablishment of catheter function after approximately 60 minutes of urokinase/plasma instillation. No patient experienced adverse effects during or after instillation. No bleeding complications occurred. The entire management procedure was easy to perform and well tolerated. In one case the instillation of urokinase and plasma failed. The explanted CVP showed that a silicon particle, which had originated during puncture, had occluded the CVP.

Table I: Patient characteristics.

\begin{tabular}{llll}
\hline Initials & Age (years) & Diagnosis & Therapy \\
\hline NK & 6 & Hemophilia & Factor VIII \\
AH & 3 & Hemophilia & Factor VIII \\
HR & 67 & Hepatocellular Carcinoma & Fluorouracil, Folic Acid \\
MA & 51 & Colon Carcinoma & Fluorouracil, Folic Acid \\
BH & 53 & Mammary Carcinoma & Fluorouracil, Doxorubicin \\
\hline
\end{tabular}




\section{Discussion}

Catheter occlusion is a common complication of longterm CVP placement. Therapeutic fibrinolytic agents like r-UK or r-tPA are used successfully to restore function of occluded CVP $[1,2]$ Generally one or two instillationsof r$\mathrm{UK}$ are required in the majority of patients. A 98.1\% patency rate is reported when treating catheter occlusions in paediatric patients with r-UK at a concentration of 5,000 IU/mL [4] However, after repeated applications of plasminogen activators, a clot may become deprived of plasminogen. This will result in the failure of further attempts.

\section{Conclusion}

The method we have described in this paper is useful in such situations. We were able to avoid catheter replacement in all five patients with thrombotic catheter occlusions that were treated with r-UK and autologous plasma. This is especially important for children.

\section{Competing interests}

The author(s) declare that they have no competing interests.

\section{Authors' contributions}

Georg Seifert was involved in acquisition of data, drafted the manuscript and has given final approval of the version to be published.

Hanno Riess was involved in acquisition of data and made substantial contributions to conception and design and has given final approval of the version to be published.

Karl Seeger was involved in acquisition of data and critically revised the manuscript and has given final approval of the version to be published.

Günter Henze critically revised the manuscript and has given final approval of the version to be published.

Anja Borgmann was involved in acquisition of data and has given final approval of the version to be published.

\section{Acknowledgements}

None

\section{References}

I. Glynn MF, Langer B, Jeejeebhoy KN: Therapy for thrombotic occlusion of long-term intravenous alimentation catheters. JPEN J Parenter Enteral Nutr 1980, 4:387-390.

2. Hurtubise MR, Bottino JC, Lawson M, McCredie KB: Restoring patency of occluded central venous catheters. Arch Surg 1980, I 15:212-2|3.

3. Collen D, Lijnen HR: Thrombolytic agents. Thromb Haemost 2005, 93:627-630.

4. Wachs T: Urokinase administration in pediatric patients with occluded central venous catheters. J Intraven Nurs 1990, 13:100-102.

\section{Pre-publication history}

The pre-publication history for this paper can be accessed here:

http://www.biomedcentral.com/1471-2407/6/103/pre pub
Publish with Biomed Central and every scientist can read your work free of charge

"BioMed Central will be the most significant development for disseminating the results of biomedical research in our lifetime." Sir Paul Nurse, Cancer Research UK

Your research papers will be:

- available free of charge to the entire biomedical community

- peer reviewed and published immediately upon acceptance

- cited in PubMed and archived on PubMed Central

- yours - you keep the copyright

Submit your manuscript here:

http://www.biomedcentral.com/info/publishing_adv.asp 